\title{
Unravelling History Using Scanning Electron Microscopy
}

\author{
E.C. Humphrey ${ }^{1}$, and T.P. Loychuk ${ }^{2}$. \\ 1. University of Victoria, Mechanical Engineering Department, Victoria, BC, Canada \\ 2. Private Researcher
}

A simple question "what fibers were used in an ancient Coast Salish blanket?" launched a collaborative effort to solve that mystery involving blankets in different museums in different countries and collaborations with First Nations from Alaska, British Columbia and Washington State (fig. 1). The effort has led to confirming several oral traditions. This story is a perfect example of how science and art can validate history.

Coast Salish weavers in the Pacific Northwest, bred a type of dog that they kept separate from the village dogs, to sheer the woolly coat for weaving into blankets. These dogs supposedly went extinct around 1900. We have found that the hair was often mixed with plant fibers and other animal hair. Material from a precontact blanket yielded woolly dog hair and fireweed. Some included plant fibers and/or down feathers, most contained mountain goat hair. Mountain goat hair was a particular favourite but became scarce in the late 1800s and the blankets often contained sheep wool. A blanket from the Burke Museum (Seattle) contained mountain goat hair, wooldog, cedar and sinew. Another at the Museum of Vancouver contained down feathers. Pre-contact material from Ozette, WA, contained woolly dog and fireweed fibers.

Sometimes the blankets were patterned with many colors. One from Juneau. Alaska had 29 colors in it. The black color was provided by human hair.

The primary means of identifying hair samples is by their scale patterns. However, some confusion flows from the observation that one species may have different patterns of scales within one hair. Moreover, taking hairs from different parts of the body of the same animal generally produces a wide variety of scalar patterns lessening the diagnostic value. Moreover, the scales on hairs in ancient blankets are often rubbed away and the hairs are very degraded (fig. 3). Thus, using only one criteria of "scale pattern" is insufficient to confidently identify a species.

When we began a study of hairs to reveal alternate diagnostic characteristics which could be used for identifying different species, we found that making transverse and longitudinal cross-sections of the hair to show the medulla and cortex thicknesses, became the most important diagnostic approach (Fig 2). The species differences were much clearer. However, the difficulty in cutting consistently clean and accurate longitudinal sections of the hairs, which were often thinner than the blade used, led to trying several techniques to get better results.

Scanning electron microscopy provides great surface detail but is limited because of the similarities of the scalar patterns in different species and the differences of scalar patterns within the same hair. We needed light microscopy to give internal features of the thinner hair. The thicker guard hairs were too dense for the light microscope but were relatively easy to section longitudinally for the SEM.

During this journey, the path diverted in several directions but always came back to establishing that the weavers were very resourceful and used materials available to them. Wool or hair such as from mountain 
goat, woolly dogs, sheep, coyote were sometimes mixed with plant fibers such as flax, dogbane, cedar, fireweed, stinging nettle, cotton (fig. 5). One of the oral traditions confirmed by this study is the use of diatomaceous earth (fig. 4). The makers of these ancient blankets have shown themselves to be exquisite practitioners of the art of weaving and are still showing us a thing or two.
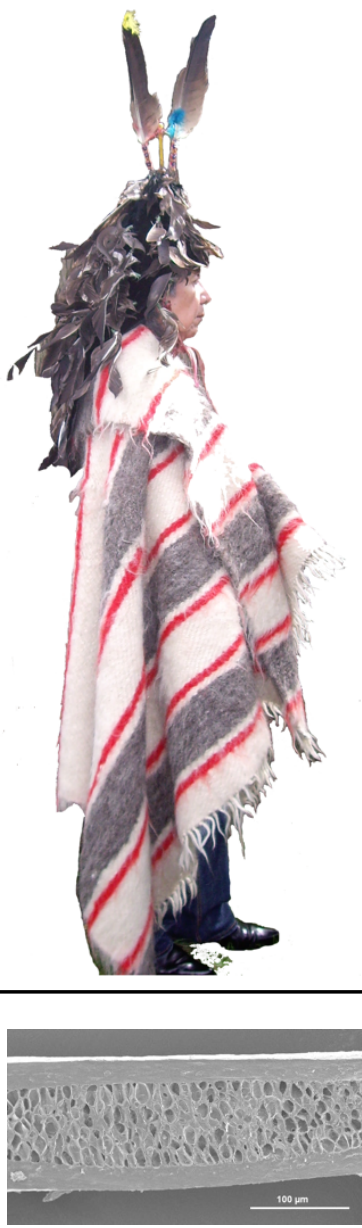

Mountain goat longitudinal section

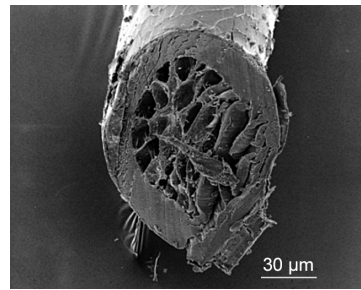

Mountain goat transverse section

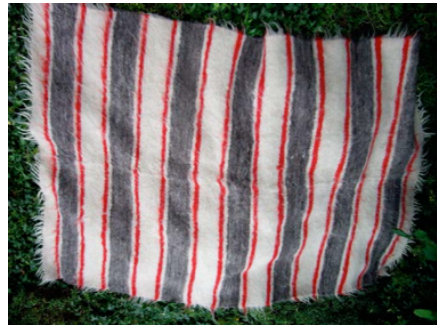

TPL blanket

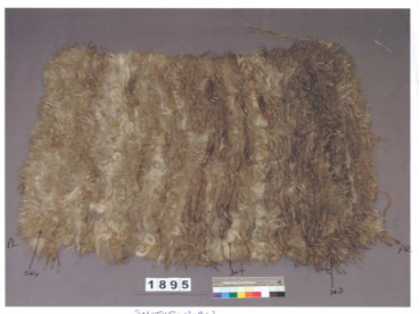

Smithsonian skin blanket

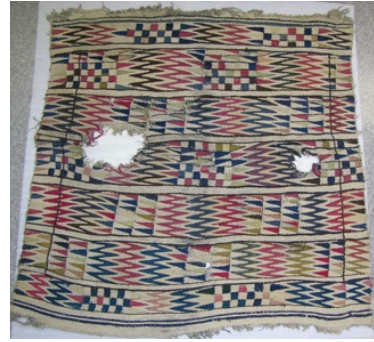

Juneau blanket

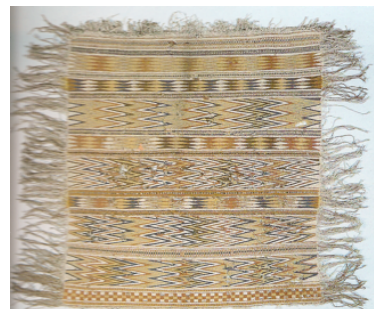

Perth blanket

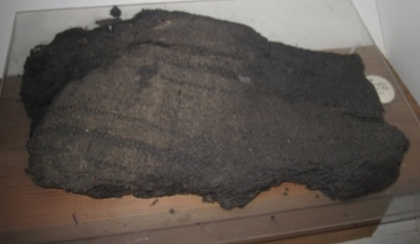

Makah Cultural and Research Museum

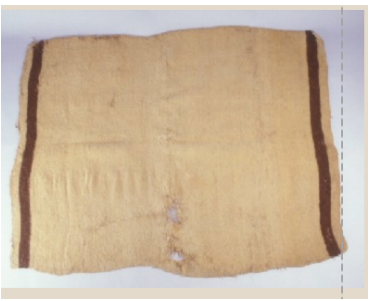

Burke Museum blanket

Fig. 1 some of the many blankets investigated

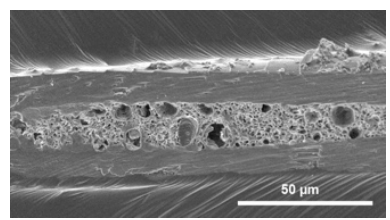

Wooldog longitudinal section

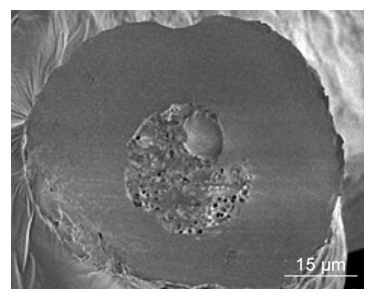

Wooldog longitudinal section

Fig. 2 longitudinal and transverse hair sections

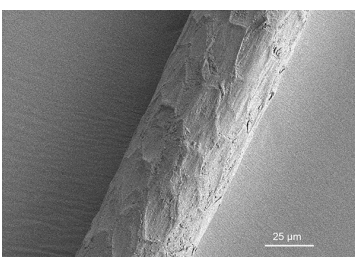

Fig 3. Degraded hair

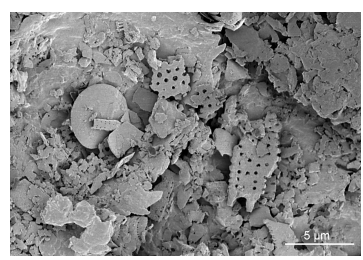

Fig 4. Diatomaceous earth in North Van blanket

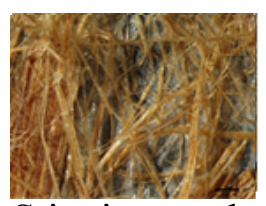

Stinging nettle

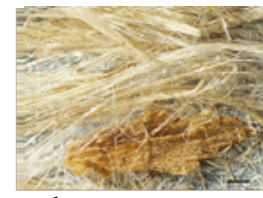

Flax

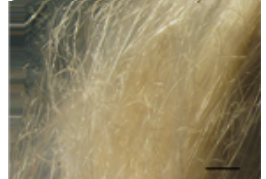

Fireweed

Fig 5. some of the plant fibers used in blankets Scale bar $500 \mu \mathrm{m}$ 